Pikas, E., Koskela, L., Treldal, N., Knotten, V. and Bølviken, T. (2018). "The Dual Nature of Design Management" In: Proc. $26^{\text {th }}$ Annual Conference of the International. Group for Lean Construction (IGLC), González, V.A. (ed.), Chennai, India. pp. 647-657 DOI: doi.org/10.24928/2018/0537. Available at: www.iglc.net.

\title{
THE DUAL NATURE OF DESIGN MANAGEMENT
}

\author{
Ergo Pikas', Lauri Koskela ${ }^{2}$, Niels Tredal ${ }^{3}$, Vegard Knotten $^{4}$, Trond Bølviken ${ }^{5}$
}

\begin{abstract}
Design management profession has probably got the least attention in the construction industry. One reason could be the lack of explicit conceptualizations about its nature, subject matter and principles. In this article, a conceptual design management framework is proposed on the premise that design management is the management of a structured system of object and subject-oriented, technical and social design activities. Additionally, an example of a mediating visual model is proposed to facilitate the discussions about design activities and design management in academia and practice. The two major premises of this research are 1) as design management is the management of design activity, it is dependent on the way design is conceptualized; and 2) design is a human activity, but not a thing (e.g., representation) or an event (e.g., decision-making).
\end{abstract}

\section{KEYWORDS}

Design management, activity theory, design activity, design system, shared mental models.

\section{INTRODUCTION}

Although the first practices of managing design were already documented in Germany as early as in 1907 (Schwartz 1996), it is only in the recent decades that design management gained widespread scholarly interest. Despite numerous efforts, the design of buildings is still suffering from many failures (Pikas et al. 2015). Literature review reveals that one primary cause of these problems could be the poor conceptualizations of design management (Koskela et al. 2002; Pikas et al. 2015). The rest of this article builds on this insight and proposes a design management framework together with a visual model as a mediating artefact to facilitate the conversations about design management within the design management academia, and hopefully, also in practice.

\footnotetext{
Technical University of Denmark, DTU Management Engineering, ekas@dtu.dk, Tallinn University of Technology, Faculty of Engineering and Aalto University, Department of Civil Engineering 
The importance of using frameworks has been illustrated by Woods (2009): "In science we need frameworks that hit an intellectual sweet spot for their research communities - the frameworks must provide conceptual leverage without being fatuously simple (overly "lumped") or distractingly complex (needlessly "split"). The form of such frameworks is as much about the order that our own minds require to move forward effectively as it is about the accuracy with which some aspect of the world has been captured."

This study is conceptual in nature. Based on a literature review, the emphasis is placed on the conceptualizations of design activity and its relation to design management. The paper is divided into three parts: the first section addresses the conceptualization of design from the activity approach and theory perspectives; the second section addresses the lean and social conceptualizations of design management. In the third section, a framework and a visual model are constructed and proposed.

\section{DESIGN ACTIVITY}

Design activity is a complex phenomenon, defined in many different ways and on different levels. There is hardly any consensus on what design is (Love 2000). At the macro level, the design is the whole process and practice of design concerning the design project organization, including considerations about the specific stages, phases, and elements in the design process (Cash and Kreye 2017). At the meso and micro levels, a design activity can be defined concerning the individual designer or collective of designers and their mental and practical actions and operations (Cash and Kreye 2017).

\section{DESIGN PARADIGMS}

No design conceptualization takes place in a vacuum, and the same applies to any scientific discipline (Kuhn 1962). Particular views on design conceptualization determine the focus of analysis, its content (attended and disregarded features) and expected outcomes. This is known as the design paradigm, which describes the different perspectives, assumptions and prescriptions underlying the design research (Stumpf 2001).

In this study, the underlying assumption is that design is an activity of a human agent, and thus, any theorization about designing can be understood only in a human context. This is supported by several design researchers (Bedny and Meister 2014; Cash and Kreye 2017; Love 2000).

Bedny and Meister, referring to the leading Soviet philosopher G. Shchedrovitsky, argued that the $20^{\text {th }}$ century epistemologies can be divided into two contrasting, nonexclusive, approaches (Bedny and Meister 2014):

- Naturalistic approach - concerned with the descriptive studies of transforming the unmediated experiences directly into knowledge about the existence of objects and phenomena in nature; 
- Activity approach - the meaning of human life (things and events, features and relationships of those things and events) and its context can only be revealed through a process of human activity (making it useful for practical interventions).

The majority of design paradigms tend to fall under the naturalistic approach, for example, the science of the artificial proposed by Simon (1981), while fewer consider design from the activity approach perspective (Love 2000). In the following, the four well-known design paradigms are briefly reviewed.

Dorst (1997) studied two paradigms of designing, 'rational problem-solving' and 'reflective practices'. Stumpf (2001) added to this list of design paradigms 'design as a social process' and design as 'hypothesis testing'. Dorst (1997) differentiated the design paradigms based on three dimensions of the design conceptualization: models of the designer (features of the designers, how designers reason and behave), the design task (the intricacies of how designers understand design tasks) and the dynamics of the design process (activities of designers divided into macro, meso and micro-level processes). The study of these aspects of designing is collectively referred to as the design methodology (Cross 1984): "the study of principles, practices and procedures of design".

The positivist information-processing conceptualization of design activity uses analytical and symbolic approaches and methods to problem-solving (Simon 1981). The 'second-generation' design paradigm was proposed by Rittel (1984), who defined design as a social process, subject to the 'wicked' and 'tamed' problems.

The third design paradigm, developed on the idea of 'analysis-by-synthesis' (Lawson 2006), emerged as a response to the limitations of the rational and social design paradigms and was named hypothesis testing (Broadbent 1984). The fourth design paradigm is referred to as the reflective practice (Schön 1984), describing designing as a dynamic, continuous, cyclic and unfolding process of individual learning.

The first two (the rational and social views) lean towards the naturalistic approaches of design conceptualization; while hypothesis testing and experiential learning lean towards the activity based conceptualizations of designing. However, these design paradigms are not necessarily exclusive and could form complementary frames of reference (Bedny and Meister 2014).

\section{ACTIVITY THEORY}

Activity theory (AT) originated as an alternative approach to the Western behaviorist approach to the study of human psychology. AT was initially formalized by the Russian philosophers and scientists S. L. Rubinshtein (1889-1960) and A. N. Leont'ev (19041979) (Bedny and Meister 2014). There are several Western interpretations, of which one well known is by Engeström et al. (1999). In the present article, the structural activity theory approach by Bedny and Meister (2014) is followed.

AT describes design activity as a hierarchically organized system of conscious and unconscious, goal-directed actions and operations. Design activities are either object or subject-oriented, technical or social (Cash and Kreye 2017). 
In the technical activities, designers use different architectural and engineering instruments (e.g., BIM) to transform design object between different design states. In the social activities, interactions between two or more design team members are constituted in the information exchanges, personal interactions and mutual understanding. The social activities are mediated by different internal (e.g., language) or external (e.g., video conferencing) instruments (Bedny and Meister 2014). It is important to note that social relationships also matter in the object-related activities as an inner dialogue about the given situation, surrounded by norms and standards (Engeström et al. 1999).

Bedny and Meister (2014) differentiated between object, goal, result and motives. The object (either concrete or abstract; e.g., steel structure or building information model) of design activity is either what goes through a change process or is being explored by a designer according to the goal of the design activity. The goal is "a conscious cognitive representation of the desired future result of activity accepted or not, transformed or not, before or during activity" (Bedny and Meister 2014). The result is the actual outcome of the design activity. Motives (the gap between the need and actual) are what energize the goal, connecting needs and objects (Bedny and Meister 2014). Figure 1 adopts the highlevel structural description of the human activity from Bedny and Harris (2005).

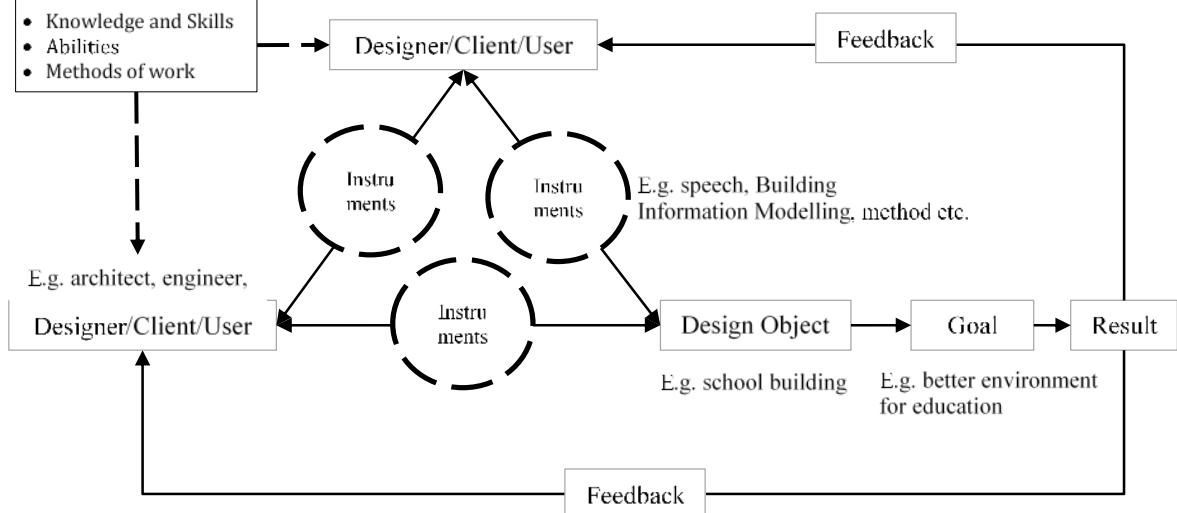

Figure 1. A description of an activity system (adapted from Bedny and Harris (2005)). Based on this description of AT, a building design activity can be defined concerning the purposes of a building project and designers' behaviors (Bedny and Harris 2005):

The building design is a purpose directed system where motivation, cognition, and behaviors are integrated with respect to the 'bringing-into-being' of a new building.

In the following, the different levels of human activity based on the AT formalism are summarized, consisting of conscious activities, tasks and actions, and unconscious operations:

- Activity: subjectively distinct periods of human activity associated with fulfilling a motivation. As designers can have more than one motivation at any time, then more than one activity can be progressed at one time (Bedny and Meister 2014). An example of building design could be an activity focused on developing a design embodiment. 
- Task: a temporally and subjectively distinct part of an activity, required for the achievement of a goal under specific conditions (Bedny and Meister 2014). Within the context of building design, an example of a task could be the dimensioning of a primary part of a building structure.

- Action: mental and practical actions are the last conscious level of design activity (fragment of task), always associated with the duration, place and a designer. Actions have a recursive loop structure, with multiple forward and backward interconnections (Bedny and Meister 2014). Bedny and Harris (2005) proposed a one-loop model for action, consisting of four actions (see Figure 2): Identify (acceptance and/or transformation of action's goal(s)); generate (development of ideas, alternatives, conditions and plans for the design action); develop (preparation/creation of designs, (e.g. calculations, drawings, specs and/or models, and their testing/demonstration (e.g. BIM simulations, prototypes)); and evaluate/decide (communication and decisions for further actions). An example of action could be the calculation of loads as a part of the task of dimensioning the primary building structures.

- Operations: actions are further divided into unconscious mental and practical operations; i.e., a continuous process and structured system of processing units as well as the system of internal mental processes underpinning behavior (Cash and Kreye 2017). For example, the movement of a hand for drawing a line or memorizing an idea.

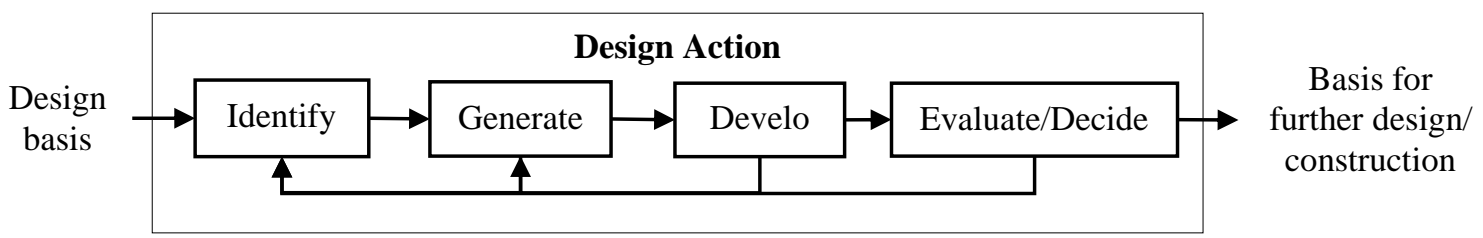

Figure 2. Design action as a one-loop system (adapted from Bedny and Harris (2005)).

To summarize, AT is a holistic psychological approach to the study of human activity. The two first levels of the activity structure (activities and tasks) are the objects of study, the two last (actions and operations) are the units of analysis. This means that actions and operations are more basic, from which the objects of study emerge.

\section{LEAN DESIGN MANAGEMENT}

In this section, the focus shifts from describing the design activity to describing the managerial activities. Although the different methods of lean design management embed the management of the social aspects (such as the Language-Action Perspective (LAP) in the Last Planner System (LPS) (Ballard 2000)), it is essential to clarify the function of design management concerning the social dimensions more explicitly.

\section{CONCEPTS IN LEAN DESIGN MANAGEMENT}

According to the Transformation, Flow and Value (TFV) theory, lean design project (system) management has three functions, each with its specific managerial principles (Koskela et al. 2002): design system design, design system operation and design system 
improvement. The idea of 'design system design' concerning three goals (value, transformation, and flow) is well established in the lean community (Ballard et al. 2001).

The operations management of a design system through the different phases of the project is divided into three management functions: planning, execution, and control of design operations (Koskela et al. 1997).

According to Koskela et al. (1997), the partial models for conceptualizing the different dimensions of planning include management-as-planning and management-asorganizing. The former is responsible for the structuring and sequencing of the design tasks, and latter is responsible for the structuring of the environment to contribute to purposeful acting - to avoid making-do (Koskela 2004). In the design process, inflows include (Bølviken et al. 2010): expectations and demands, decisions, manning, methods and tools, and dialogue. LPS divides planning into four levels, each with their specific focus and planning horizon: master (entire project), phase, lookahead, and weekly/daily planning (Ballard 2000), incorporating the technical and social considerations.

Execution can be conceptualized by using the two partial models, the classical communication theory and the language-action perspective (Koskela et al. 1997). The former is focused on the efficient transmission of information, and later on the promisebased management of the design process.

Managerial control also consists of two partial models (Koskela et al. 1997): the (mindless) thermostat model based on control theory and the scientific experimentation model (plan-do-check-act) by Shewhart and Deming.

The design system improvement is focused on the feedback of lessons learned through the different phases of the design process and the project in general (Koskela et al. 2002). First run studies have been proposed to prototype and test the capability of operations to meet targets and make corrections when necessary. Metrics on different levels of resolution, such as key performance indicators (KPIs) or Percent Plan Complete (PPC), have been proposed to facilitate the process of learning (Ballard 2000).

\section{SOCIAL ASPECTS OF DESIGN MANAGEMENT}

In addition to the technical level of design management, Rekola et al. (2012) identified three other essential levels of design management: the substance level, the communicational/interaction level, and the personal level. These levels correspond to the social dimensions of design management, especially crucial in the early stages of design when the design activity is language rich framing and re-framing of views (Stumpf 2001).

\section{Development and Maintenance of Shared Understanding}

The development of a shared understanding between the design team members has been studied through the development of shared mental models (sMM). As most of the designing happens within the heads of individual designers, especially in the early stages of design, the concept of mental models (MM) is valuable for understanding the cognitive processes of designers (Casakin and Badke-Schaub 2017).

MMs are simplified internal representations of the world constructed by individuals for gaining and processing information, depending on the context and social setting in 
which these MMs are constructed. MMs influence the team's communication and performance, and aid the coordination and adaptation of the design activity (Casakin and Badke-Schaub 2015).

The studies on sMM in teams have been divided into three major types, the MM of the design task, of the design process and the individual's or the team's MMs (Edmondson and Nembhard 2009). A few concepts either from the perspective of an individual or collective have been proposed to describe the interpretative dimensions of design tasks and processes.

Stumpf (2001) proposed a concept for describing how learning and the development of shared understanding emerge from the individual level to the level of the design team. The concept combines design rhetoric and Schön's reflective practices, and consists of collective framing, naming, moving and reflecting processes. Within the context of organizations, Nonaka and Takeuchi (1995) proposed the processes of internalization, socialization, externalization, and combination.

The difference in the two approaches is that Stumpf (2001) focused on the development of the sharedness of mental models (design-as-argumentation), while Nonaka and Takeuchi (1995) were interested in tacit knowledge (design-as-knowledgeexplication). Therefore, although this is not their interpretation, Stumpf (2001) is concerned with the development and maintenance of common ground, while Nonaka and Takeuchi (1995) are concerned with the development and maintenance of boundary objects (e.g., BIM) and standardized methods (e.g., LPS) (Koskela et al. 2016; Pikas et al. 2016).

Thus, in the social dimension, design management is responsible for the facilitation of communication to develop sMM throughout all phases of the design process by using different means to explicate the tacit knowledge. This requires a shift from focusing on the problem solving to facilitating the co-evolution of shared understanding of needs, requirements, ideas and solution principles.

\section{DEVELOPMENT OF A FRAMEWORK AND CONSTRUCTION OF MEDIATING ARTEFACTS}

In this section, different concepts on design and design management activities are synthesized to propose a new design management framework.

Before this can be done, the relationships between the hierarchical dimensions of design activity and the different levels of management need to be clarified. Ballard and Tommelein (2016) propose a convention for breaking tasks into different levels of detail based on the Gilbreth's motion analysis. However, there is an essential difference between the AT theory and the Western approach. The Western approach to human psychology was behaviorist in nature, focusing on the practical actions and operations of humans, neglecting the mental ones. In the Russian AT, the behavior necessarily included the mental actions and operations in addition to the practical ones (Bedny and Meister 
2014) ${ }^{6}$. Consequently, as illustrated in Table 1, it is not a coincidence that LPS has four levels of management considerations.

Table 1. Relationships between design activity and design management functions.

\begin{tabular}{|l|c|c|c|c|c|}
\hline Focus of Study & \multicolumn{2}{|c|}{ Objects of Study } & \multicolumn{2}{c|}{ Units of Analysis } \\
\hline Activity Theory & \multicolumn{2}{|c|}{ Activity } & Task & Action & Operation \\
\hline Building Design Example & Project & Phases & Tasks & Actions & Operations \\
\hline Lean Design Management & \multicolumn{2}{|c|}{ Design, Operate, Improve } & \multicolumn{2}{|c|}{ Plan, Execute, Control } \\
\hline Last Planner System & \multicolumn{2}{|c|}{ Master plan (Should) } & $\begin{array}{c}\text { Phase (Pull) } \\
\text { Planning (Should) }\end{array}$ & $\begin{array}{c}\text { Lookahead (Can), Weekly (Will), } \\
\text { First Run Studies, Metrics }\end{array}$ \\
\hline
\end{tabular}

Within Table 2, the dual nature of design management is illustrated, including the technical and social aspects. In the technical view of the design system design, the TFV theory is instructive. In the social view, the design-as-argumentation and design-asknowledge-explication are useful. Thus, as part of the design system design, it is crucial to establish the necessary conditions for the design collaboration (Koskela et al. 2016): how common ground is created; goal alignment and situational awareness maintained; continuous improvement during the project encouraged; and integration with production achieved.

The design system operation is divided into three management functions: planning, execution, and control. Under planning we find the management-as-planning and management-as-organizing; under execution the communication theory and languageaction perspective; and under control, the thermostat model and scientific experimentation have been proposed to correspond to the technical and social views respectively.

The improvement of the design system can be informed by the use of metrics to illustrate the trends and systematic experimentation through the design process.

Table 2. Mapping lean design management concepts to technical and social views.

\begin{tabular}{|c|c|c|c|c|c|}
\hline & \multicolumn{5}{|c|}{ Production Management Functions } \\
\hline & \multirow{2}{*}{$\begin{array}{c}\text { 1. Design System } \\
\text { Design }\end{array}$} & \multicolumn{3}{|c|}{ 2. Design System Operation } & \multirow{2}{*}{$\begin{array}{c}\text { 3. Design } \\
\text { System } \\
\text { Improvement }\end{array}$} \\
\hline & & 2.1 Planning & 2.2 Execution & 2.3 Control & \\
\hline $\begin{array}{l}\text { Technical } \\
\text { view of design }\end{array}$ & TFV & $\begin{array}{c}\text { Management- } \\
\text { as-planning }\end{array}$ & $\begin{array}{c}\text { Communication } \\
\text { theory }\end{array}$ & $\begin{array}{c}\text { Thermostat } \\
\text { model }\end{array}$ & Metrics \\
\hline $\begin{array}{l}\text { Social view } \\
\text { of design }\end{array}$ & $\begin{array}{l}\text { Design-as- } \\
\text { argumentation } \\
\text { Design-as- } \\
\text { knowledge- } \\
\text { explication }\end{array}$ & $\begin{array}{l}\text { Management- } \\
\text { as-organizing }\end{array}$ & $\begin{array}{l}\text { Language- } \\
\text { action } \\
\text { perspective }\end{array}$ & $\begin{array}{c}\text { Scientific } \\
\text { experimentation }\end{array}$ & First Run Study \\
\hline
\end{tabular}

In the following, a visual model for the execution of design activity is proposed. The model is based on the technical and social views of design. Similar models can also be constructed for all the other pairs in Table 2. The proposed model is adapted from Bølviken et al. (2010) and further clarified based on the design activity theory. At the

${ }^{6}$ A detailed discussion of the differences is beyond the scope of this work, and need to be addressed within a future study. 
center of the model is the last level of conscious, goal-oriented design activity, namely the design actions. The dialogue in the language-action terms (including communication and argumentation, coordination and decision-making) is needed between the design team members to secure a sound design process. This conversation takes place in the context of a design task, to which a designer (or a team of designers) has committed himself in the phase planning.

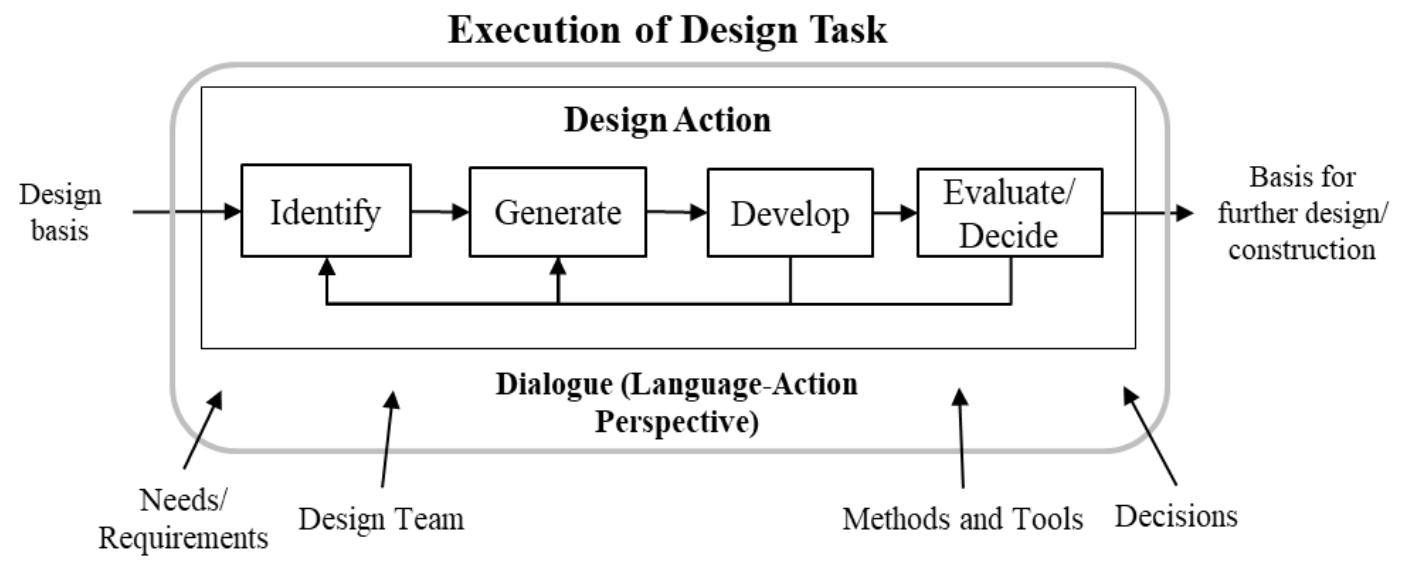

Figure 3. Design management model for the design management execution function (adapted from Bølviken et al. (2010)).

\section{CONCLUSIONS}

The design is a complex phenomenon, and so is the design management. Design management is influenced by how a design activity as such is conceptualized. In turn, this is dependent on the particular design paradigm that has been chosen by the researcher for studying and developing the descriptive as well as prescriptive concepts and practices. In this article, designing was conceptualized as a human activity, not as a thing or event. Based on these premises, a comprehensive framework supported by a visual model for conveying conceptual ideas was proposed. Holistic design management has a dual nature as design management is the management of a structured system of object and subjectoriented, technical and social mental and practical actions of design.

\section{REFERENCES}

Ballard, G., Koskela, L., Howell, G., and Zabelle, T. (2001). "Production system design in construction." Proc., Proceedings of the 9th annual conference of the International Group for Lean Construction.

Ballard, G., and Tommelein, I. (2016). "Current Process Benchmark for the Last Planner System." Project Production Systems Laboratory, University of California, Berkeley, Available at: p2sl.berkeley.edu, pp. 42.

Ballard, H. G. (2000). "The last planner system of production control." The University of Birmingham. 
Bedny, G., and Meister, D. (2014). The Russian theory of activity: Current applications to design and learning, Psychology Press.

Bedny, G. Z., and Harris, S. R. (2005). "The systemic-structural theory of activity: Applications to the study of human work." Mind, culture, and Activity, 12(2), 128-147.

Bølviken, T., Gullbrekken, B., and Nyseth, K. (2010). "Collaborative design management." Proc., Proceedings of the 18th annual conference of the International Group for Lean Construction, Haifa, Israel.

Broadbent, G. (1984). "Design and theory building." Developments in Design Methodology, John Wiley \& Son, Chichester, UK.

Casakin, H., and Badke-Schaub, P. (2015). "Mental models and creativity in engineering and architectural design teams." Design Computing and Cognition'14, Springer, 155171.

Casakin, H., and Badke-Schaub, P. (2017). "Sharedness of team mental models in the course of design-related interaction between architects and clients." Design Science, 3.

Cash, P., and Kreye, M. (2017). "Uncertainty Driven Action (UDA) model: A foundation for unifying perspectives on design activity." Design Science, 3.

Cross, N. (1984). Developments in design methodology, John Wiley \& Sons.

Dorst, C. H. (1997). Describing Design-A comparison of paradigms, TU Delft, Delft University of Technology.

Edmondson, A. C., and Nembhard, I. M. (2009). "Product development and learning in project teams: The challenges are the benefits." Journal of product innovation management, 26(2), 123-138.

Engeström, Y., Miettinen, R., and Punamäki, R.-L. (1999). Perspectives on activity theory, Cambridge University Press.

Koskela, L. (2004). "Making-Do - the Eighth Category of Waste." Proc., 12th Annual Conference of the International Group for Lean Construction.

Koskela, L., Ballard, G., and Tanhuanpää, V.-P. (1997). "Towards lean design management." Proc., Proceedings of the 5 th annual conference of the International Group for Lean Construction, 1-13.

Koskela, L., Huovila, P., and Leinonen, J. (2002). "Design management in building construction: from theory to practice." Journal of Construction Research, 3(01), 1-16.

Koskela, L., Pikas, E., Gomes, D., Biotto, C., Talebi, S., Rahim, N., and Tzortzopoulos, P. (2016). "Towards Shared Understanding on Common Ground, Boundary Objects and Other Related Concepts." The 24th Annual Conference of the International Group for Lean ConstructionBoston, USA, 63-72.

Kuhn, T. S. (1962). The Structure of Scientific Revolutions, University of Chicago Press, Chicago.

Lawson, B. (2006). How designers think: The design process demystified, Routledge.

Love, T. (2000). "Philosophy of design: a meta-theoretical structure for design theory." Design studies, 21(3), 293-313.

Nonaka, I., and Takeuchi, H. (1995). The knowledge-creating company: How Japanese companies create the dynamics of innovation, Oxford university press.

Pikas, E., Koskela, L., Dave, B., and Liias, R. (2015). "Case Study on Design Management: Inefficiencies and Possible Remedies " 23rd Annual Conference of the 
International Group for Lean Construction, O. In: Seppänen, González, V.A. \& Arroyo, P., ed.Perth, Australia, 547-557.

Pikas, E., Koskela, L., Treldal, N., Ballard, G., and Liias, R. (2016). "Collaboration in Design - Justification, Characteristics and Related Concepts." Proc., 24th Annual Conference of the International Group for Lean Construction.

Rekola, M., Mäkeläinen, T., and Häkkinen, T. (2012). "The role of design management in the sustainable building process." Architectural Engineering and Design Management, 8(2), 78-89.

Rittel, H. (1984). "Second-generation design methods." Developments in design methodology, 317-327.

Schön, D. A. (1984). The reflective practitioner: How professionals think in action, Basic Books, US.

Schwartz, F. J. (1996). The Werkbund: design theory and mass culture before the First World War, Yale University Press.

Simon, H. A. (1981). The sciences of the Artificial, Massachusetts Institute of Technology Press, Cambridge, MA.

Stumpf, S. (2001). "Analysis and representation of rhetorical construction of understanding in design teams' experiential learning." University College London.

Woods, D. (2009). "Rasmussen's SRK 30 Years Later: Is Human Factors Best in 3's?" Proc., Proceedings of the Human Factors and Ergonomics Society Annual Meeting, SAGE Publications Sage CA: Los Angeles, CA, 217-221. 